\title{
1 Dropping to escape: a review of an under-appreciated
}

\section{2 antipredator defence}

3

4 Rosalind K. Humphreys ${ }^{*}$ and Graeme D. Ruxton

5

6

7

8

9 ABSTRACT

10 9TH, UK

School of Biology, University of St Andrews, Dyer's Brae House, St Andrews, Fife, KY16

Dropping is a common antipredator defence that enables rapid escape from a perceived threat. However, despite its immediate effectiveness in predator-prey encounters (and against other dangers such as a parasitoid or an aggressive conspecific), it remains an underappreciated defence strategy in the scientific literature. Dropping has been recorded in a wide range of taxa, from primates to lizards, but has been studied most commonly in insects. Insects have been found to utilise dropping in response to both biotic and abiotic stimuli, sometimes dependent on mechanical or chemical cues. Whatever the trigger for dropping, the decision to drop by prey will present a range of inter-related costs and benefits to the individual and so there will be subtle complexities in the trade-offs surrounding this defensive behaviour. In predatory encounters, dropping by prey will also impose varying costs and benefits on the predator - or predators - involved in the system. There may be important trade-offs involved in the decision made by predators regarding whether to pursue prey or not, but the predator perspective on dropping has been less explored at present. Beyond its function as an escape tactic, dropping has also been suggested to be an important precursor to flight in insects and further study could greatly improve understanding of its 
evolutionary importance. Dropping in insects could also prove of significant practical importance if an improved understanding can be applied to integrated pest-management strategies. Currently the non-consumptive effects of predators on their prey are underappreciated in biological control and it may be that the dropping behaviour of many pest species could be exploited via management practices to improve crop protection. Overall, this review aims to provide a comprehensive synthesis of the current literature on dropping and to raise awareness of this fascinating and widespread behaviour. It also seeks to offer some novel hypotheses and highlight key avenues for future research.

Key words: dropping, antipredator defence, predator-prey interaction, behavioural ecology, evolution, biological control, integrated pest-management.

\section{CONTENTS}

I. Introduction

II. Which taxa exhibit dropping as an antipredator defence and what different forms does dropping take?

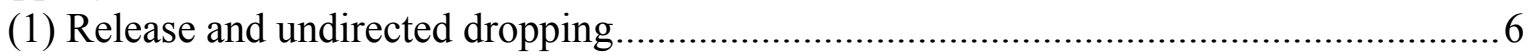

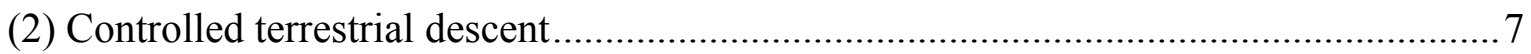

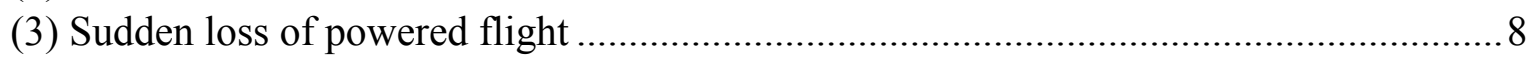

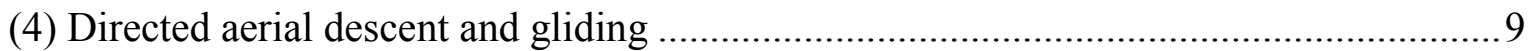

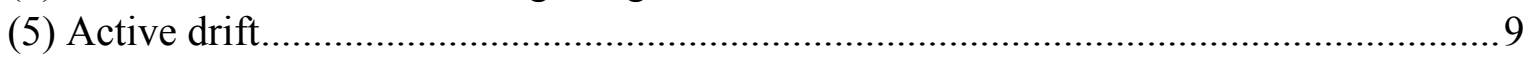

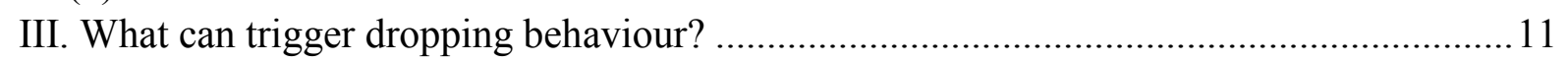

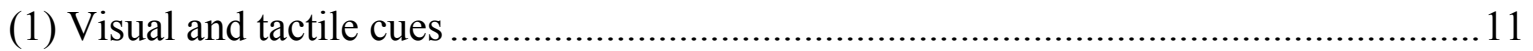

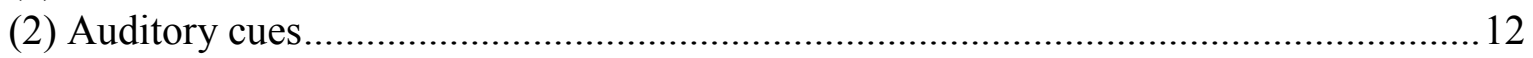

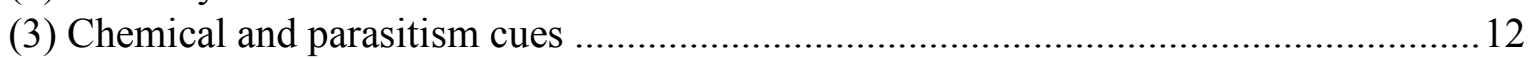

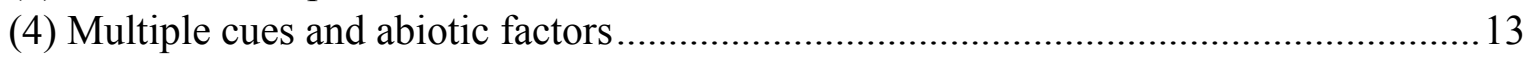

IV. What are the benefits, costs and trade-offs associated with dropping? ............................. 14

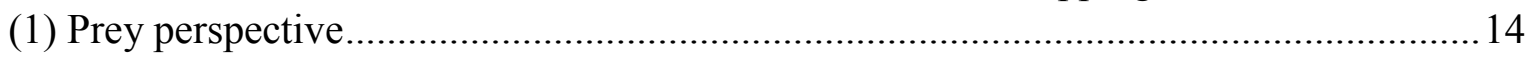

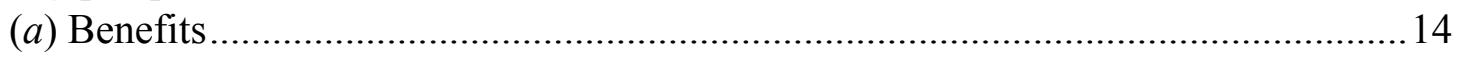

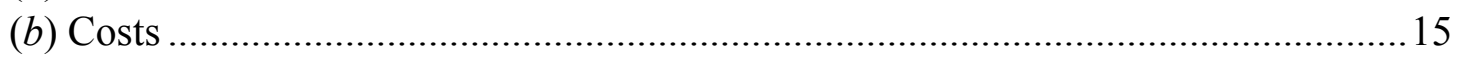

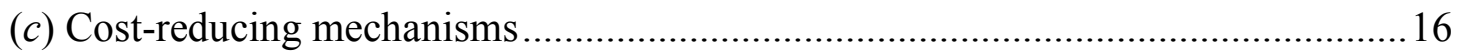

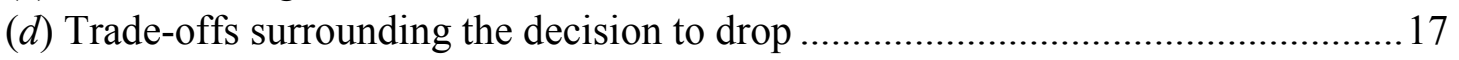

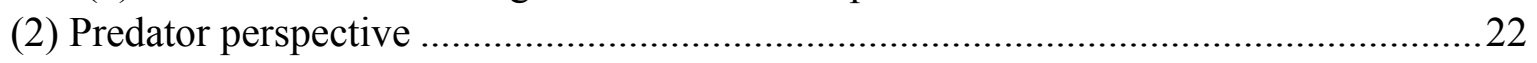

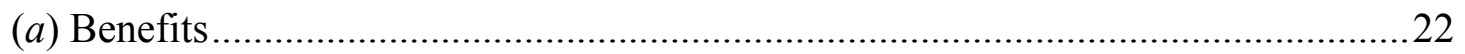

(b) Costs and trade-offs surrounding the decision to pursue prey ..............................22 
61 VI. What practical applications are there for a better understanding of dropping behaviour? 25

64 IX. Acknowledgements

65 X. References

\section{INTRODUCTION}

One of the simplest ways for an organism on a raised substrate or in the air to escape an approaching threat is to drop. Dropping behaviour immediately removes an individual from the perceived hazard - be that a predator or another source of danger (such as a parasitoid or aggressive conspecific) - at least temporarily. Broadly, as an antipredator defence, dropping is a behaviour that could literally mean the difference between life and death for the prey. In the natural world, where organisms are engaged in an ongoing 'struggle' to survive and proliferate to pass on their genes to subsequent generations, any evolved adaptations that increase the likelihood of survival and/or breeding opportunities will be of great advantage to an individual or, indeed, a species. Given that antipredator adaptations occur in almost every major taxonomic group and in every biome of the world, Ruxton, Sherratt \& Speed (2004, p. 2) rightly point out that, "as R. A. Fisher argued, their very presence tells us that predation is a phenomenon of great ecological and evolutionary significance”. Antipredator adaptations can be morphological, chemical, or - as in the case of dropping - behavioural in nature, but all have evolved to reduce the risk of predation and, ultimately, mortality, thereby increasing the fitness of the prey. In many cases, when faced with a predatory threat, a prey species has multiple antipredatory adaptations they could utilise. Some morphological defences, for example camouflage, may be deployed constantly, but where prey have the option to select a behavioural defence in response to an imminent threat they ought to select the behaviour that will best increase their chances of surviving the encounter. 
87 We define dropping as a voluntary antipredator defence whereby a prey individual uses gravity, wind or water currents to power escape from imminent threat. Dropping can either be passive, where an individual simply falls away or releases its hold on a substrate, or active, where the individual may jump away from a substrate, sometimes kicking or somersaulting in the process (Brown, 1974); as an example of this variability, Haemig (1997) describes wood ants, Formica aquilonia, both falling and deliberately jumping from trees. Whether passive or active, key to dropping is that the behaviour must result in the individual escaping in a trajectory determined primarily by the external force (gravity or bulk fluid flow) only modified modestly, if at all, by the organism itself.

This deceptively simple, but in fact very complex, behaviour is common and widespread as an antipredator defence, but (perhaps due to its lack of required morphological adaptations) it is currently under-studied. As a key antipredator defence, dropping has significant consequences for both prey and predators at both individual and population scales.

Undoubtedly, the precise cost-benefit framework surrounding dropping depends on the point of deployment within the predation sequence. Interactions between predators and their prey can be usefully broken down into a sequence of stages comprising: (1) encounter (spatial and temporal proximity), (2) detection, (3) identification, (4) approach, (5) subjugation, and (6) consumption (Caro, 2005; Endler, 1991). In the literature, antipredatory defences employed by prey during stages 1-4 (ahead of subjugation) are referred to as 'primary defences', serving to influence the likelihood of the predator physically contacting the prey. So-called 'secondary defences' act once subjugation or contact has begun (stages 5 and 6). Unusually, dropping escape can be deployed either as a primary defence [see Barnett et al. (2017), Brown (1974) and Clegg \& Barlow (1982) for some examples of dropping pre-subjugation] or a secondary defence [see Castellanos et al. (2011) and Cloudsley-Thompson (1995) for some examples of dropping post-contact], suggesting that the timing of this escape behaviour 
can be varied in an adaptive way. Generally, we might not expect prey to drop as soon as they perceive a predator as they will not definitely be at risk of attack unless the predator has already detected them, identified them as prey and begun their approach. In many circumstances there will potentially be significant costs associated with dropping, for example, if there are other predators foraging below the prey's initial position, and so it may be adaptive to delay escape - and avoid the costs of dropping altogether - until a predation attempt is undoubtedly imminent. However, while dropping earlier in the predation sequence leads to more frequent dropping in prey, dropping later in the predation sequence runs the risk that a predator is successful in attacking before the prey gets a chance to drop, or that the predator can track and pursue prey that have dropped more readily. We expect the timing of dropping responses to specific predator attacks to be context dependent.

This review seeks to highlight the broad taxonomic distribution of dropping as an escape tactic, ranging from relatively passive undirected dropping using gravity, water, or wind, to relatively active and directed dropping in species that employ a form of gliding. We then detail a range of situations that can trigger the behaviour, considering visual, tactile, auditory, chemical, and parasitism-related triggers as well as the importance of multiple cues and abiotic factors in some situations. The costs, benefits, and trade-offs to dropping for both prey and predators are then discussed, including its use in combination with other defence mechanisms - such as tonic immobility (Honma, Mappes \& Valkonen, 2015; Humphreys \& Ruxton, 2018) - or cost-reducing behaviours - such as silk drop-lines (Castellanos \& Barbosa, 2006; Fitzpatrick, Troubridge \& Maurice, 1994; Johnson et al., 2007; Sugiura \& Yamazaki, 2006) or aerial righting (Meresman, Ben-Ari \& Inbar, 2017; Ribak et al., 2013). This review also aims to draw attention to the importance of this under-appreciated antipredator defence, not only for the individual organisms and populations affected, but also because of its potential to improve our understanding of the evolution of insect flight (Dudley 
et al., 2007; Dudley \& Yanoviak, 2011; Yanoviak, Kaspari \& Dudley, 2009) and how improved knowledge of dropping could be applied practically to benefit ecological modelling and agriculture. Finally, we offer a number of outstanding questions that could stimulate fruitful future research in this area.

\section{WHICH TAXA EXHIBIT DROPPING AS AN ANTIPREDATOR DEFENCE AND} WHAT DIFFERENT FORMS DOES DROPPING TAKE?

As an antipredator defence that does not necessarily require specialist morphological adaptations or complex display behaviours, dropping is commonly used as an escape tactic across a wide range of taxa. However, from simple, undirected dropping dependent on gravity, to more controlled active dropping, and dropping in underwater contexts, there is a range of forms dropping can take to ultimately achieve the same antipredator function.

\section{(1) Release and undirected dropping}

Often examples of terrestrial dropping escape consist straightforwardly of a release from a raised substrate and an undirected fall to whatever lies beneath. In many cases, an approaching threat may be aerial in nature, as is the case for several Mediterranean lizard species that respond to perceived avian predators by dropping from bushes to the ground (Vitt et al., 2002). Interestingly, though, some birds themselves - such as certain African bulbuls (Pycnonotus barabatus and Andropadus latirostris) and the frugivorous speckled mousebird (Colias striatus) - have also been reported as 'dropping like rocks' when they have been perched in trees (Caro, 2005; Lima, 1993). By so doing they escape into dense, underlying vegetation in order to avoid attacks from raptors.

Undirected dropping involving release from plants has been undoubtedly best studied in insects, however, and these small taxa can potentially encounter threats approaching from 
above, below or from level surroundings. The wealth of study of insect dropping is likely due to the behaviour's prevalence in insects and the relative ease of study in these taxa. Most commonly, aphids are the focus of dropping research (Francke et al., 2008; Gillespie \& Acheampong, 2012; Gish, Dafni \& Inbar, 2011; Losey \& Denno, 1998c; Ma \& Ma, 2012; Wyckhuys et al., 2008), but lepidopterans (Castellanos \& Barbosa, 2011; Greeney, Dyer \& Smilanich, 2012; Perović et al., 2008; Zhou, Meng \& Li, 2017) are also well known for dropping - most commonly in their larval stages, but also as adults (Honma et al., 2015). Important predatory insect taxa, including ladybirds (Ben-Ari \& Inbar, 2013; Lucas, Coderre \& Brodeur, 1997) and spiders (Blackledge \& Pickett, 2000; Cloudsley-Thompson, 1995; Jackson, Rowe \& Wilcox, 1993; Uetz et al., 2002), also drop to escape predation themselves.

\section{(2) Controlled terrestrial descent}

Like lizards and smaller birds, many species of primate - which despite being relatively large taxa are not apex predators - experience predation threats from raptors. Here dropping from tree canopies (sometimes with the help of vines) into lower branches or undergrowth can serve as an effective defence (Barnett et al., 2015, 2017; de Luna et al., 2010; de Souza Martins, de Lima \& de Sousa e Silva, 2005; Lledo-Ferrer et al., 2009; Wright, 1998). To avoid injury, the descent will likely be more controlled in these larger taxa than in insect species - some of which may well possess hard integuments that help them withstand dropping - such that individuals plan their route down to some extent. Compared to smaller taxa, though, it may be that dropping in primates is a less costly behaviour in terms of the energy and time expenditure required for returning to suitable locations once a threat has passed. Often primate dropping behaviour is accompanied by alarm calls (see references above), but sometimes such warning calls occur in response to species that only resemble predators (Barnett et al., 2018). This has been suggested to occur in such species as the red- 
nosed cuxiús (Chiropotes albinasus) because although cautiously reacting to a 'pseudopredator' may reduce the time available for foraging or other activities, fitness is enhanced overall by not risking becoming a potential predator's dinner (Barnett et al., 2018).

\section{(3) Sudden loss of powered flight}

Not all prey species that exploit gravity when dropping in an undirected way start off based on a substrate. For many insects fully capable of flight, dropping from the air suddenly during a bout of powered flight remains an important antipredator defence against flying predators such as bats (Miller \& Olesen, 1979; Miller \& Surlykke, 2001). Several bird species have also been reported as dropping out of the air to escape predation. Beyond simple escape dives, where small passerines often sharply pull up after dropping vertically over sea to evade falcons (Hedenstrom \& Rosen, 2001), sometimes birds do completely drop with the help of gravity to reach refuge in water. Belted kingfishers (Megaceryle alcyon) have been observed suddenly plunging down into water when being pursued by hawks (e.g. Cooper's hawk, Accipiter cooperii, and sharp-shinned hawks, Accipiter striatus) over a river (Johnson, 1925; Kirby \& Fuller, 1978; Skinner, 1928); in this case, dropping appears to be the first stage in the overall escape strategy as the kingfisher rapidly rises back out of the water facing a completely different direction and speeds off, meanwhile the hawk must attempt to arrest its momentum and readjust its attack direction. Where there is no body of water below, and only hard ground, some birds still escape mid-air attacks through dropping. Mourning doves (Zenaida macroura) and European starlings (Sturnus vulgaris) both perform sudden breastfirst plunges into the ground to escape predation, but the substantial risk of injury associated with this tactic suggests it may be a truly 'last-ditch' defence (Caro, 2005; Lima, 1993). 
212 Many arboreal vertebrates have extended simple dropping escape behaviour into directed aerial descent (gliding at steep angles) or 'classical gliding' (gliding at shallow angles), including some species of lizard (Dudley et al., 2007; McGuire \& Dudley, 2005; Mori \& Hikida, 1994), frogs (Emerson \& Koehl, 1990; McCay, 2001) and even snakes (Socha, 2002). These descents are slower than simple undirected release from a given substrate, making them a more controlled form of dropping. Many small mammals also use classical gliding (Jackson, 2012; Jackson, 2000), both for escape and travel functions. Classical gliding in terrestrial vertebrates was likely an important precursor to the evolution of powered flight (Dudley et al., 2007; Dudley \& Yanoviak, 2011). Directed aerial descent has only fairly recently been described in a variety of wingless arboreal insects too (Yanoviak, Dudley \& Kaspari, 2005; Yanoviak, Fisher \& Alonso, 2008; Yanoviak, Munk \& Dudley, 2011, 2015; Zeng et al., 2015). It is important to note here that, while dropping from the air and directed aerial descent fall under our definition of dropping, those species such as flying squirrels that have extensive morphological adaptation for gliding used for routine movement through the environment as well as escape from predators are best seen as a separate phenomenon. Species well adapted to glide are able to modify the trajectory of falls significantly so that their dropping is less directly impacted by forces such as gravity.

\section{(5) Active drift}

Having considered terrestrial and aerial dropping enabled primarily by gravity - but also potentially wind - it is also important to consider aquatic taxa that utilise water flow, sometimes alongside gravity, when evading predation. Many molluscan prey species in tidepools have been reported to escape from predaceous species, such as starfish and sea stars, by releasing their attachment to the substratum, flattening their mantles dorsoventrally, 
and gliding away in the surf (Bullock, 1953; Dayton et al., 1977; Hoffman, 1980; Lam,

237 2002). This escape behaviour strongly resembles directed aerial dropping but currently remains under-studied. More appreciated in the literature at present is a similar behaviour that is seen in running waters, such as streams and rivers. Where water flows, benthic invertebrates can actively escape from their predators by releasing their foothold and entering the water column in a behavioural defence known as 'active drift' (Brittain \& Eikeland, 1988). Active drift is one of several mechanisms of 'invertebrate drift' seen in running waters, a broader topic that has been the focus of many studies over the past few decades [see Brittain et al. (1988), Naman, Rosenfeld \& Richardson (2016) and Wooster \& Sih (1995) and references therein]. Active drift differs from most examples of terrestrial dropping, as the prey typically escapes via an upwards and horizontal trajectory rather than downwards.

Nonetheless, we consider it a form of aquatic dropping due to its voluntary initiation, antipredator function, and its exploitation of an external force (here water currents rather than gravity) in the avoidance of an imminent threat.

Intriguingly, a different mechanism of dropping has been observed in conjunction with tonic immobility in two species of predatory cichlid fish - Haplochromis livingstoni and Parachromis friedrichsthalii. These fish appear to mimic a corpse by falling down through the water column and lying inert on the substrate as part of their hunting tactic (McKaye, 1981; Tobler, 2005); however, as an antagonistic tactic deployed to deceive potential prey, this behaviour far from qualifies for our definition of dropping as an antipredator defence. The prevalence of dropping as an antipredator defence across such a wide range of taxa gives an indication of how effectively it must function as an adaptive and flexible escape behaviour. The evident convergent evolution of such a defence across multiple groups of very different animals demonstrates how important and fitness-enhancing behavioural adaptations can be, despite not necessarily occurring alongside specialist morphological adaptations. Due 
to the bulk of the dropping literature currently consisting of studies using insects this review will consequently focus on insect interactions with predators and parasitoids. However, work on other taxa is drawn in where possible and many of the broader concepts discussed and suggested research areas will apply equally to all species where dropping can influence survival and fitness. We encourage further study of this conceptually simple but subtly complex defence within the context of all the predator-prey interactions in which it occurs.

\section{WHAT CAN TRIGGER DROPPING BEHAVIOUR?}

\section{(1) Visual and tactile cues}

The most obvious trigger for antipredator dropping is the approach of a predator, following the prey's detection of the predator. In primates and other terrestrial vertebrates, approaching avian predators are often detected visually (Barnett et al., 2017; de Luna et al., 2010; LledoFerrer et al., 2009; Vitt et al., 2002). Insect vision is less understood than primates', but it is thought that substrate-borne vibrations may sometimes be more important to insects' detection of an approaching predator (Castellanos \& Barbosa, 2006). Direct contact with a predator will also be an important trigger for dropping, and it has been found that the sensory hairs of Orgyia leucostigma (Lymantriidae) caterpillars enable stimulus-specific - and therefore predator-specific - responses depending on the velocity of hair-bending they experience (Castellanos et al., 2011). Specifically, O. leucostigma caterpillars predominantly drop in response to high hair-bending velocities - similar to those caused by more forceful, rapid predators like the wasp Polistes fuscatus and the spined assassin bug Sinea diademaand predominantly walk away in response to low hair-bending velocities - similar to those caused by the slower-attacking stink bug Podisus maculiventris. 
Flying insects avoiding predation by bats use one main trigger to drop: bat echolocation calls

287

(Miller \& Olesen, 1979; Miller \& Surlykke, 2001). In a fascinating case of possible convergent evolution, Rosen, Levin \& Hoy (2009) describe how females of the parasitic fly Ormia ochracea have evolved the same evasive behaviour as their cricket (Gryllus rubens) hosts, dropping towards the ground upon detecting bat echolocation calls. As disrupting flight by dropping could be energetically costly, some species of moth have evolved sophisticated abilities to discriminate between the calls of bats that are flying nearby looking for prey ('early attack') and calls of these bats that have detected prey and are moving into pursuit ('late attack') - this discrimination allows these moths to use only the truly threatening "late attack" calls to trigger dropping behaviour (Corcoran, Wagner \& Conner, 2013; Ratcliffe et al., 2011). While some have suggested that prey species should benefit most by defending as early as possible during predator-prey encounters (Endler, 1991; Fuiman \& Magurran, 1994), this is a clear case where taking defensive action later on in the predation sequence can be more beneficial, corroborating the conclusion of Bateman, Vos \& Anholt (2014) that there is no universal ecological or evolutionary advantage to defending early in the predation sequence.

\section{(3) Chemical and parasitism cues}

In aphids a key trigger to drop to avoid either predators or parasitoids is alarm pheromone, (E)- $\beta$-farnesene, release by conspecifics (Harrison \& Preisser, 2016; Keiser, Mondor \& Koenig, 2015; Montgomery \& Nault, 1977; Roitberg \& Myers, 1978; Schwartzberg et al., 2008). Parasitoids are important natural enemies of insects and it is thought that dropping may be the most common behavioural defence against them (Gross, 1993). Intriguingly, in aphids different symbionts may (Dion et al., 2011) or may not influence the likelihood of 
dropping in response to the presence of parasitoids (Lavy et al., 2015). Often in parasitoidhost encounters, dropping behaviour occurs as a response to - rather than in anticipation of parasitism (Chau \& Mackauer, 1997; Gillespie \& Acheampong, 2012). Here, the trigger for dropping could relate to the physical external experience of parasitism or an internal chemical cue; future work could pick apart the trigger, or triggers, at play. It has been suggested that aphids altruistically commit 'adaptive suicide' when parasitized to protect uninfected kin (McAllister \& Roitberg, 1987; McAllister, Roitberg \& Weldon, 1990), but this has been questioned (Latta, 1987; Tomlinson, 1987).

\section{(4) Multiple cues and abiotic factors}

Information from multiple senses can be combined to trigger antipredatory dropping, such as the detection of alarm pheromone release from conspecifics alongside vibrations caused by the movement of an approaching threat (Clegg \& Barlow, 1982). Fascinatingly, multiple cues have recently been recorded as key to triggering dropping in invertebrates escaping incidental ingestion by mammalian herbivores (Ben-Ari \& Inbar, 2013; Gish, Dafni \& Inbar, 2010). The combination of the heat and humidity of mammalian breath has been found to trigger dropping in coccinellid beetles (Ben-Ari \& Inbar, 2013) and Uroleucon sonchi aphids (Gish et al., 2011). Additionally, pea aphid (Acyrthosiphon pisum) nymphs appear to combine breath cues with vibration cues to avoid erroneous dropping, which would be particularly costly at such a young life stage (Gish, Dafni \& Inbar, 2012).

As well as biotic cues, abiotic factors may interact with triggers to dropping. Higher temperatures can increase predator foraging rate and, therefore, the vibrations sensed by prey (Brodsky \& Barlow, 1986). Heat stress itself may (Ma \& Ma, 2012) or may not trigger dropping, possibly depending on the clone or species studied (Stacey \& Fellowes, 2002) future work could explore this. There are clearly many potential triggers for escape dropping, 
and almost certainly there is yet more to discover about the combination of senses and cues utilised by non-insect taxa in particular in detecting approaching predators. Whatever the trigger for dropping, the costs, benefits and trade-offs associated with the behaviour will influence the decision to drop in prey and its impact on predators, whether they choose to pursue the prey or not.

\section{WHAT ARE THE BENEFITS, COSTS AND TRADE-OFFS ASSOCIATED WITH}

\section{DROPPING?}

\section{(1) Prey perspective}

\section{(a) Benefits}

For prey, the most obvious benefit of dropping is the immediate escape from a threat.

Dropping presents an immediately effective antipredator escape option and therefore in many situations it could offer the greatest benefit to prey fitness, relative to other tactics. As an example, Minoretti \& Weisser (2000) found that pea aphids that try to walk away from seven-spot ladybird (Coccinella septempunctata) predators are often re-encountered. Dropping takes advantage of external forces - in this case, gravity - in order to exploit the path of least resistance, so that escape from enemies is simple and rapid. This benefit applies to avoidance of predators, parasitoids (Gross, 1993), and intra-guild predators where different instars of competing species vary in size and/or defences (Lucas et al., 1997; Raak-van den Berg, De Lange \& Van Lenteren, 2012; Sato, Yasuda \& Evans, 2005). A subtler benefit of dropping in all circumstances where prey make their escape from a particular resource, for example a feeding area on a plant, may be that post-dropping the prey individual experiences a better resource, for example a feeding area on a plant of greater quality, but this is an example of a more complex, long-term benefit that is at present under-studied. 
Despite any immediate and long-term benefits, dropping comes with a suite of fitness costs.

These can include energetic costs such as temporary distancing from resources, energetic loss while locating a subsequent resource, or selecting a poorer subsequent resource than the original. For insects such as aphids, reduced feeding time likely damages larval fitness (Johnson et al., 2007), increases development time for nymphs and is thought to reduce reproductive capacity in adult life (Agabiti, Wassenaar \& Winder, 2016). Even where aphids at any life stage are successful in locating a new plant on which to feed after dropping, their lifetime fecundity is likely to be impaired due to the loss of feeding time and energy expended in searching (Nelson, 2007; Roitberg, Myers \& Frazer, 1979). By reducing fecundity, this key 'non-consumptive effect' of predators - and parasitoids (Fill, Long \& Finke, 2012; Ingerslew \& Finke, 2017) - can substantially reduce prey population growth (Nelson, 2007; Nelson, Matthews \& Rosenheim, 2004; Nelson \& Rosenheim, 2006). For dropped individuals, the risk of mortality may also increase through: $(i)$ exposure to new predators (Losey \& Denno, 1998a,c; Winder, 1990), (ii) exposure to harsh or harsher environmental conditions (Perović et al., 2008; Roitberg \& Myers, 1979; Ruth et al., 1975), or (iii) time spent finding a suitable resource post-dropping. There is also the additional risk of simply being pursued and consumed by the original predator. Strikingly, from a population perspective, incidents of dropping can lead to important changes in the spatial organisation of prey (Fievet et al., 2007; Minoretti \& Weisser, 2000; Winder et al., 2014) and it is likely that such changes may increase the susceptibility of remaining prey to future attacks (Agabiti et al., 2016). 
384 There are clearly significant costs to dropping as an antipredator defence, particularly for undirected forms of dropping, and so it is no surprise that some species have evolved mechanisms to reduce these costs. Wingless pea aphids have recently been observed exhibiting an aerial-righting mechanism, whereby they assume a stereotypic posture when dropping that rotates them to a stable orientation. This improves their chances of clinging on to leaves that they encounter as they fall, thus lowering the likelihood of encountering risks to mortality on the ground (Meresman et al., 2017; Ribak et al., 2013). Similarly, lizards such as Anolis carolinensis use their tails as a mid-air stabliser when jumping and falling to allow for coordinated landing on small branches after escaping predators. However, sometimes lizards will lose their tails by autotomy as a separate defence mechanism (Bateman \& Fleming, 2009), and until their tail grows back stability when falling is compromised (Gillis, Bonvini \& Irschick, 2009). Lizards with autotomised tails, therefore, likely face greater potential risks when dropping and so must include their tail loss in decisions regarding their choice of antipredator behaviours.

A more commonly observed cost-reducing tactic than aerial righting in insect taxa is the production of silk thread 'drop-lines' - also known as 'draglines' (Blackledge \& Pickett, 2000) and 'life-lines' (Sugiura \& Yamazaki, 2006). Lepidopteran larval dispersal behaviour often involves the use of drop-lines in 'silking' and subsequent 'ballooning' on the wind (Cox \& Potter, 1990; Moore \& Hanks, 2004; Terry, Bradley \& Vanduyn, 1989; Zalucki, Clarke \& Malcolm, 2002), but drop-lines are also important for avoiding threats (Castellanos \& Barbosa, 2006). After dropping a short distance with silk to avoid a predator, larvae may continue to drop further (Johnson et al., 2007) or lose contact with the plant because of environmental factors such as strong winds (Perović et al., 2008). Alternatively, sometimes 407 larvae climb back up drop-lines once the perceived threat has passed, thus avoiding the costs 
associated with losing their original position (Fitzpatrick et al., 1994; Sugiura \& Yamazaki, 2006).

However, some parasitoids have evolved a remarkable countermeasure to drop-lines, whereby they locate the silk support line and slide down to their prey (Yeargan \& Braman, 1986). More incredibly, Yeargan \& Braman (1989) describe how the hyperparasitoid Mesochorus discitergus overcomes the dropping defence of green cloverworm Plathypena scabra (Lepidoptera) in order to oviposit in the larval primary parasitoids inside alreadyparasitised caterpillars. Here, where a green cloverworm larva hangs from a leaf on silken threads, the hyperparasitoid usually hangs by its hind tarsi from the edge of the same leaf before reeling in the caterpillar, by pulling upward on the silken thread. The hyperparasitoid females then distinguish between green cloverworms parasitized by one of their hosts, Cotesia marginiventris, and those that are unparasitized, holding and probing parasitized ones further (Yeargan \& Braman, 1989). Even where prey do not face parasitoid countermeasures, potential drawbacks to drop-lines may include silk production costs, the risk of strong winds (Perović et al., 2008), or the presence of flying predators. Not all silk-producing insects use drop-lines when dropping, so it is likely that related costs - such as dangling exposed to flying predators in mid-air - are less worth risking for some species in some situations. A detailed look at how silk-spinning ability and the potential for alternative defensive behaviours affect willingness to drop as lepidopteran larvae develop would be valuable.

(d) Trade-offs surrounding the decision to drop

Whether prey have cost-reducing mechanisms to employ or not, the decision to drop will be guided by a number of important trade-offs concerning the relative benefits and costs of dropping to escape any perceived threat. Abiotic factors may influence the decision to drop even when they themselves are not the immediate trigger for dropping; for example, the daily 
cycle and illumination have been suggested to influence colonisation of plants in potato aphids (Macrosiphum euphorbiae) (Narayandas \& Alyokhin, 2006) and so may influence mortality risk post-dropping. Similarly, high soil temperatures can prove fatal to dropping insects (Perović et al., 2008; Ruth et al., 1975) and so the heat of the surrounding environment must be traded off with the immediacy of predatory danger. Abiotic factors such as temperature and light may be more likely to influence the fitness of insect taxa than larger taxa that utilise dropping, as smaller taxa experience greater variation between microclimates and, proportionally, drop a much greater distance (that will require more energy to recover a position from) relative to their body size. Pea aphids have been described as 'assessing' risk and are less likely to drop when their environment is hot and dry (Dill, Fraser \& Roitberg, 1990). Of course, any assessment of a potentially risky situation need also include a number of biotic factors.

Traits of an individual's starting location or substrate itself should undoubtedly feed into any decision to drop, where prey leaves a desired resource during escape. If a resource is high quality it would be costly to abandon it for potentially lower-quality resources and individuals are less likely to drop from it (Dill et al., 1990). For insects, dropping likelihood may also depend on where the individual is located on a plant - Clegg \& Barlow (1982) suggest that the stems of plants may be more dangerous for aphids than the undersides of leaves. The architecture of a plant may also influence the trade-off between danger and dropping if it influences how likely a dropped individual is to land on a lower part of the plant. It would be interesting to investigate whether herbivores select particular types of plants or particular places on plants on which to feed in part because such site selection improves the effectiveness of dropping as an antipredator strategy. Defensive morphological adaptations or other structural components of a plant may additionally help prey avoid predators or parasitoids (Obermaier et al., 2008), reducing the necessity of escape and 
therefore the frequency of dropping defence. An interesting additional consideration for insect prey species is whether plants are attended by ants or not; myrmecophilous aphids, for example, appear to be more dependent on ants for protection from predators than their own defensive tactics such as dropping (Nault, Montgomery \& Bowers, 1976; Suzuki \& Ide, 2007).

Alongside plant factors, where relevant, traits of the prey themselves will influence their decision to drop. If dropping from a feeding resource, whether prey are specialist or generalist feeders could have important implications for their likely success at finding suitable locations at which to feed post-dropping (Castellanos \& Barbosa, 2011). For insects requiring particular host plants, host-finding and dispersal abilities will be very important (Ben-Ari, Gish \& Inbar, 2015; Bierzychudek et al., 2009). Of course, host-finding abilities may be linked with plant factors, but there is still much to learn about how insects locate their host plants (Döring, 2014) and more studies regarding host-finding abilities may develop our understanding of the costs of dropping under different conditions. Life-history traits and prey state have also been found to influence the benefits and costs that will accompany dropping for prey individuals. In a theoretical model, Uroleucon jacea aphids with high relative gonadal investment or poor somatic energy states feeding on Centaurea jacea are predicted to be less willing to drop in response to predator attack due to their short survival probabilities when food uptake stops (Stadler, Weisser \& Houston, 1994).

In a similar vein, ontogeny could affect the trade-offs experienced by prey, but while adult or later-instar insect prey (Cornell, Stamp \& Bowers, 1987; Losey \& Denno, 1998c) are sometimes the more willing to drop, it is often the more juvenile stages in various insect taxa that drop most readily (Awan, 1985; Cloudsley-Thompson, 1995; Francke et al., 2008; Jackson et al., 1993; Lucas et al., 1997). Smaller lepidopteran larvae, for example, are perhaps less likely to be pursued by the original predator, but are also more susceptible to 
starvation through taking more time to reach a suitable feeding site post-dropping. If dropping is more costly to young, it would be adaptive for them to employ more sensory modalities to detect the level of threat. Gish et al. (2012), for example, found that young pea aphids avoid erroneous dropping when evading incidental ingestion by mammalian herbivores by dropping mostly in response to a combination of breath stimulus and vibrational stimulus. Ontogenetic differences in defence tactics are also seen in response to parasitism (Chau \& Mackauer, 1997; Cornell et al., 1987). Willingness to drop at different life stages may be largely determined by relative vulnerability either to predators or climatic conditions (Perović et al., 2008). Additionally, while a couple of studies have suggested that prey density does not affect dropping behaviour in pea aphids (Harrison \& Preisser, 2016; Losey \& Denno, 1998c), Day et al. (2006) found that prey density was a significant influence on aphid dropping behaviour. Intraspecific differences, reproductive state, and associations with more intricate secondary defence mechanisms could also be explored further. In part relating to some of the prey traits already mentioned, as well as more complex traits such as personality (Schuett et al., 2011), the trade-offs of dropping for prey are also thought to vary with species (Losey \& Denno, 1998a), race (Kunert et al., 2010), strain (Zhang et al., 2016), and clone (Braendle \& Weisser, 2001; Lowe \& Taylor, 1964; Schuett et al., 2011, 2015). Interestingly, kin recognition may influence dropping likelihood, even in non-social aphids (Muratori, Rouyar \& Hance, 2014), but more work should explore this further. For any species, dropping will not be the only defensive option and behavioural trade-offs will be made depending on any given situation. Dropping is often used in combination with other defence mechanisms and, for example, its deployment in conjunction with subsequent tonic immobility (or death-feigning) (Humphreys \& Ruxton, 2018) may be more effective against certain enemies than dropping alone, as has been reported in such diverse insect taxa as spiders (Blackledge \& Pickett, 2000; Jackson et al., 1993) and moths (Honma et al., 2015). 
508 The 'decision' to utilise dropping as an escape tactic may also depend on the potential for 509 alternative behavioural adaptations or tactics in given situations (Ohno \& Miyatake, 2007).

510 For example, when under feeding stress pea aphids tend to kick at Aphidius ervi parasitoids

511 rather than drop, to minimise the likelihood of energy shortfall (Villagra, Ramírez \&

512 Niemeyer, 2002). For birds that 'choose' to drop to the ground (Lima, 1993) or into water

513 (Johnson, 1925; Kirby \& Fuller, 1978; Skinner, 1928), it could be rationally assumed that the 514 obvious escape method of flight is not always the wisest defence against larger and faster raptors. Environmental factors may also affect the behavioural trade-offs made, for instance prey may choose between dropping or startle displays depending on the underlying ground cover, with dropping only proving the more appealing option if there is somewhere to hide available below (Ruxton et al., 2004).

519 Distance to safe cover below may also influence the decision to drop, where the endpoint depends on gravity. From the perspective of avian species seeking to escape from pursuing predatory birds, Hedenstrom \& Rosen (2001) analysed three aerial escape strategies and concluded that if prey are close enough to safe cover a vertical dive escape may be effective, even though smaller prey species will possess lower terminal diving speeds than that of their predators. Considering the influence of the underlying environment on insect prey, habitat complexity may also impact how easily dropped prey could locate new plants, how likely predators are to pursue dropped prey, and the effectiveness of dropping relative to other escape tactics; all of these factors deserve further study.

528 The type of predator may also determine the best defensive behaviour as, for instance, flightcapable insects may still choose to drop where their chances of flying escape are limited by dangers from above (Ben-Ari \& Inbar, 2013). The predator:prey size ratio - often influenced by the instar stages of both sides - will also influence the effectiveness of running, kicking or 532 dropping as defensive strategies (Brown, 1974; Dixon, 1958; Evans, 1976; Hoki, Losey \& 
533 Ugine, 2014). More generally, different predators have been observed to elicit different 534 dropping rates in the same insect prey species (Castellanos \& Barbosa, 2006; Castellanos et 535 al., 2011; Day et al., 2006; Losey \& Denno, 1998c). Future research could manipulate the 536 magnitude of perceived predatory risk and predator density to explore further the predatory 537 triggers for dropping. But prey species are not alone in experiencing trade-offs in dropping situations; predators themselves will potentially experience benefits and costs that require decisions to be made regarding prey pursuit.

\section{(2) Predator perspective}

\section{(a) Benefits}

543 When individuals drop they risk exposing themselves to new predators, and it is these new predators that can greatly benefit from dropping behaviour; instead of searching for and pursuing prey themselves, prey simply drops down (or indeed, flows downstream by active drift) to them. Interestingly, a laboratory study by Losey \& Denno (1998b) showed that the combined predation rate of foliar-foraging (Coccinella septempunctata) and ground-foraging

548 (Harpalus pennsylvanicus) predators of pea aphids was almost double the sum of their individual predation rates when only one type of predator was present. The strength of the synergistic interaction between the predator types suggests that dropping behaviour elicited by foliar-foraging predators greatly benefits the ground-foraging predators and has great importance to the suppressive effect of predator complexes.

(b) Costs and trade-offs surrounding the decision to pursue prey

555 For the predators that lose out on prey which have dropped to escape, the antipredator 556 behaviour involves only costs. Predators will experience costs of reduced food uptake and 557 foraging efficiency (Francke et al., 2008) and parasitoids can experience reduced fecundity 
558 (Niku, 1976). One way to reduce these costs may be to pursue dropped prey. Many insect559 eating birds employ a 'diving after' behaviour to retrieve dropped prey items - although this

560 has energetic costs, it requires less energy than seeking and acquiring new prey (Lohrl, 1978).

561 Certainly, some insect predators do pursue their prey, for example, Sceliphron caementarium

562 mud-dauber wasps vigorously pursue spiders that have dropped from their webs, and have

563 been observed to crawl around under webs in gradually enlarging circular patterns to locate

564 their fallen prey (Blackledge \& Pickett, 2000). However, few studies have explored the trade-

565 offs that may influence predators' willingness to pursue dropped prey.

566 It might be reasonable to assume that prey size, and therefore energy content, would

567 influence pursuit likelihood, with larger prey items being worthier of chasing. However, 568 some predators may prefer to attack younger and smaller prey that are less able to defend 569 themselves by kicking or running away, for example (Duran Prieto et al., 2016), so in some 570 cases the converse could be true. Some predators of aphids also prefer to attack particular 571 colour morphs as well as size (Farhoudi et al., 2014), so this may also affect their pursuit 572 likelihood. Of course, despite prey preferences, physical factors such as the distance dropped 573 would likely have a significant bearing on the decision to pursue prey. Logically, distance 574 would correlate negatively with pursuit likelihood, as the greater the distance dropped the 575 more time and energy will be required for pursuit and, if the predator hunts in vegetation or in 576 the air, for the subsequent return to typical foraging height. Another prey-related factor that 577 could present a trade-off for predators considering pursuit may be the prey density remaining 578 at the initial encounter point versus the density that has dropped away. We suspect that if 579 there are numerous prey still available, a predator is unlikely to waste time searching for a 580 dropped individual. This may be complicated, though, if a great number - perhaps the 581 majority of a colony or group, for example - of prey items simultaneously drop (potentially 
triggered by conspecific alarm pheromone in the case of aphids). Future studies would do well to pick apart these complexities.

Alongside prey factors, we propose that predator state should influence the decision to pursue dropped prey. A predator's hunger state, general physical condition, and perhaps reproductive stage may affect its willingness to pursue a prey item and suffer any potential energetic costs in doing so. As well as the risk of not finding dropped prey, amounting to wasted time and energy, predators may also 'weigh up' the risk of encountering their own predators on an underlying substrate, or further downstream in the case of active drift. In some cases, predators may also just be too slow to feasibly 'chase' dropped food items. We may also expect that some predators learn that certain types of prey in given situations are likely to drop and so these predators may alter their foraging strategies accordingly. As far as we are aware, there is a current dearth of knowledge about the trade-offs of dropping experienced from the predator's perspective and we would encourage researchers to pick up and explore some of the ideas suggested above.

\section{NON-ANTIPREDATOR FUNCTIONS OF DROPPING}

The function of dropping behaviour may not be restricted to avoiding predators. When not being used to escape enemies, voluntarily falling is sometimes deployed by invertebrates as a shortcut to the ground or to access high-quality food patches (Haemig, 1997; Ohzora \& Yano, 2011). In fact, more controlled dropping behaviour - known as 'directed falling' or directed aerial descent - has been reported in a number of wingless ant species (Yanoviak \& Dudley, 2006; Yanoviak et al., 2005; Yanoviak et al., 2008, 2010) as well as spiders (Yanoviak et al., 2015) and stick insects (Zeng et al., 2015). Directed aerial descent is considered a form of gliding, but it occurs at steeper angles than 'classical gliding' (Dudley et al., 2007). Directed aerial descent appears to have evolved independently in multiple lineage of ants and, unlike 
gliding frogs for which the behaviour also has multiple independent origins (Emerson \&

608

609

610

611

612

613

614

615

616

617

618

619

620

621

622

623

624

625

626

627

628

629

630

631

Koehl, 1990), ant species in which directed aerial descent occurs do not show obvious external morphological differences from species within the same genus that do not exhibit directed aerial descent (Yanoviak et al., 2011). The occurrence of directed aerial descent in wingless insects suggests that insects have been engaged in controlled dropping behaviours prior to the origin of wings (Dudley \& Yanoviak, 2011; Yanoviak et al., 2009). Selective pressures associated with remaining within an elevated foraging habitat may have motivated the antecedents to flapping flight from controlled dropping in lineages which are now volant (Dudley et al., 2007) and so, evolutionarily, dropping in primitive insects was likely an important precursor to insect flight (Hasenfuss, 2002).

Alongside the potentially vital role dropping may have played in the evolution of insect flight, it is important to consider the role dropping may have on the co-evolution of natural enemies. Chau \& Mackauer (1997) report how the parasitoid wasp Monoctonus paulensis preferentially attacks smaller, first-nymphal instars of pea aphids over larger and, in terms of resources for offspring development, more profitable instars in part because they were less at risk of dropping after successful parasitism. Dropping, as an antipredator defence, will presumably have impacted the foraging tactics of predators, as well as the host choice and oviposition behaviour of parasitoids, over evolutionary history and is likely to continue serving as an important behaviour in the ongoing arms race between natural enemies and their prey.

\section{WHAT PRACTICAL APPLICATIONS ARE THERE FOR A BETTER}

\section{UNDERSTANDING OF DROPPING BEHAVIOUR?}

A greater understanding of dropping would be useful to integrate into models and studies of insect population dynamics (Agabiti et al., 2016), and - where dropping is costly to prey - 
may also help to explain the invasion success of some predatory species (Hoki et al., 2014; Raak-van den Berg et al., 2012). Increased understanding of the complexities of dropping may be particularly important in the many cases where it is a common non-consumptive effect of natural enemies on pest species of agricultural crops. This could be of increasing importance across the globe as ongoing climate change is likely to influence the population dynamics of crop pests and their surrounding ecosystems (Kambrekar et al., 2015; Michaud, 2010; Wang et al., 2015). Of more practical use would be integrating insights about dropping behaviour into current pest management strategies, aiming to mitigate some of the serious yield losses caused by some pests that drop [for example, aphids (Dedryver, Le Ralec \& Fabre, 2010)].

Some insecticides are already thought to trigger dropping behaviour (Dixon \& McKinlay, 1992), which could influence pests' subsequent growth, reproduction, and crop-damaging abilities. But, increasingly, purely chemical control of pests is problematic due to such issues as pests developing resistance (Bass et al., 2015, 2014; Dedryver et al., 2010; Springate \& Colvin, 2012), damage to non-target species (Blacquière et al., 2012), other ecological issues (Geiger et al., 2010; Goulson \& Kleijn, 2013), and legislative restrictions. With the move away from chemical control, or at least to reduced chemical control, assisting the natural function of biological pest control could be an effective avenue for agriculture. Natural enemies are important and often effective controllers of crop pests (Chambers et al., 1986; Schmidt et al., 2003; Symondson, Sunderland \& Greenstone, 2002) and the value of biological pest control to agriculture worldwide has been estimated at $\$ 417$ billion per year (Costanza et al., 1997). However, the non-consumptive effects of 'biocontrol' natural enemies are currently under-appreciated in the pest-control literature and drawing knowledge about dropping behaviour into pest-management strategies could provide some novel improvements. 
657 Predators will suppress prey populations in part through the costs of induced defensive 658 behaviours - such as dropping - alongside their direct consumptive effects (Nelson \&

659

660

661

662

663

664

665

666

667

668

669

670

671

672

673

674

675

676

677

678

679

680

681

Rosenheim, 2006). Several studies have drawn attention to a synergistic effect - mediated by dropping - of foliar-foraging and ground-based predators controlling prey (Grez, Zaviezo \& Mancilla, 2011; Winder, 1990; Winder et al., 2014, 1994). Predator interactions could be particularly important in developing biological pest control (Crowder \& Jabbour, 2014), where it may also be the case that the role of parasitoids has previously been underappreciated (Schmidt et al., 2003). Of course, multiple predators may interact antagonistically (Meisner et al., 2011) and a range of other inter-related factors, such as the availability of alternative prey for generalist predators (von Berg et al., 2009), will complicate attempts to determine the overall effectiveness of pest control. But increased knowledge of dropping behaviour in predator-prey interactions could certainly help to draw out some of the more subtle impacts of predators and therefore help guide both the choice of biological control species - natural or introduced - and how to create the best conditions to prevent dropping escape behaviour giving pest species a fitness advantage, whether this advice relates to the predator involved, traits of plants, or environmental conditions. Intraguild predation is another important element to explore when aiming to develop integrated pest-management strategies (Colfer \& Rosenheim, 2001; Rosenheim et al., 1995), and as Sato et al. (2005) point out, there is a need for studies exploring the fate of some predatory taxa once they have used dropping to escape intraguild predation.

The implementation of a biological control system factoring in dropping need not necessarily be used in isolation as a pest-management strategy. While some types of chemical control seem to have long-term negative effects on natural biological control (Geiger et al., 2010; Krauss, Gallenberger \& Steffan-Dewenter, 2011), this is not to say that certain chemical treatments cannot be used effectively in combination with biological control (Gentz, 
Murdoch \& King, 2010). For any sustainable and safe pest-management strategy, a total systems approach is needed (Lewis et al., 1997), but incorporating findings about dropping into any management plan could only improve our understanding of how best to control pests while maintaining a thriving ecosystem.

\section{OUTSTANDING QUESTIONS AND OPPORTUNITIES FOR FUTURE}

\section{RESEARCH}

Dropping is already known to be a widespread antipredator escape defence, but at present its importance is under-appreciated and there is still much to learn. Considering both what may influence the decision to drop and what the consequences of dropping are for prey and their predators, there is a need for a greater exploration of abiotic factors, plant traits, variables in the underlying environment, prey factors and predator factors. Rather than repeating the specific knowledge gaps outlined above, we here draw attention to a few additional suggestions for future research before laying out what we find to be the most exciting unresolved questions.

Ideally, well-designed field studies in natural conditions could be employed to investigate the impact of abiotic conditions on dropping behaviour, for insects in particular, such as weather and temperature. The influence of changing light conditions and diel period might be particularly well explored by this means. Visual cues might be utilised by some taxa when detecting threats or locating suitable food sources post-dropping; Gish \& Inbar (2006) suggested that future studies should address insect prey's ability to discriminate between visual cues, and time of day may well influence behavioural decisions. The sensitivity of prey to environmental sounds, such as moving branches or rainfall, would also be interesting to explore through field studies, as reacting defensively to non-threatening noises would presumably incur needless fitness costs. More generally, as laboratory results do not always 
reflect field studies on dropping (Braendle \& Weisser, 2001; Raak-van den Berg et al., 2012), more field studies - or at least more natural design elements in experimental studies (such as real instead of artificial predators) - will shed more light on dropping behaviour.

Considering predators in particular, interactions between multiple predators should be explored further to see where predators act synergistically (Losey \& Denno, 1998b) or antagonistically (Traugott et al., 2012) in their control of prey. It may be interesting to research whether there are any situations where foliar-foraging predators benefit from the presence of ground-foraging predators, although Losey \& Denno (1998b) found no evidence of this. It is possible that, through using cues of different ground-based predators, studies may find that prey are sometimes less willing to drop despite also detecting foliar-based predators. Alternatively, prey may still drop but not all the way to the ground, or when they hit the ground they might flee to new plants with foliar-foraging predators on them in their hurry to escape from ground-foraging predators; these possibilities certainly warrant further investigation. More exploration of the frequency of predators pursuing dropped prey and the factors that influence this decision could also be valuable.

Another avenue for research could look into whether the specific trigger for dropping affects subsequent behaviour. Phelan, Montgomery \& Nault (1976) suggested that aphids dislodged by alarm pheromone disperse by increasing their rate of locomotion and decreasing their orientation to vertical images. Perhaps different triggers affect post-dropping behaviour differently and, if so, perhaps dropping is more or less attractive to prey depending on the trigger.

From a broader evolutionary perspective, any improved understanding of the behavioural ecology of dropping could help us explain why some species related to taxa that do drop do not utilise this escape tactic themselves, e.g. bird cherry-oat aphids (Rhopalosiphum padi) (Long \& Finke, 2014). Learning more about the contexts that instigate dropping will help us 
pick apart the evolution of dropping as an effective antipredator tactic. Dropping behaviour may also be a key factor in the evolution of insect flight, and any work that builds on our understanding of that is at least as valuable as studies presenting mechanisms for the evolution of flight in pterosaurs or early birds; arguably, flight in insects is an even more essential topic to explore due to the vast quantities of flying insects that inhabit the planet. Overall, there is still a lot to learn about dropping, but to us the most exciting and untapped questions for this topic are: (1) what factors are key in influencing the occurrence and consequences of dropping behaviour, both in the short and long term? (2) When do predators pursue dropped prey, and what factors influence this decision? (3) Why do some taxa that could drop as a defence tactic not utilise the behaviour against predators and/or what conditions bring about dropping as a defence? (4) What role did dropping behaviour play in the evolution of insect flight? (5) How could dropping behaviour be effectively exploited as part of integrated pest-management strategies?

\section{CONCLUSIONS}

(1) We define dropping as a voluntary antipredator defence whereby a prey individual uses gravity, wind or water currents to power escape from an imminent threat. The behaviour must result in the individual escaping in a trajectory determined primarily by the external force only modified modestly, if at all, by the organism itself.

(2) Antipredator dropping behaviour has been recorded across a wide range of taxa and is thought to be the most common antipredator defence in insects.

(3) Dropping can be triggered by a number of different biotic and abiotic cues. Biotic cues can include chemical triggers (e.g. alarm pheromone), mechanical triggers (e.g. contact with a predator), and other types of sensory trigger (e.g. the heat and humidity of mammalian breath). 
757

758

759

760

761

762

763

764

765

766

767

768

769

770

771

772

773

774

775

776

777

778

779

780

781

(4) Despite the immediate escape benefit that dropping provides prey with, the overall impact of dropping on a prey individual's fitness will be influenced by many factors relating to: the prey itself, the potential for cost-reducing tactics or alternative defensive behaviours, the predator(s) faced, the traits of the resource abandoned, and the surrounding or underlying environmental conditions. The decision to drop, therefore, has significant context-dependent consequences.

(5) For predators that lose prey to dropping, dropping will be costly and their subsequent decision whether to pursue prey may be influenced by traits of the dropped prey, the availability of other prey, abiotic factors, and the state of the predator itself. Interestingly, new predators that encounter the dropped prey will benefit from the behaviour, such that overall predator complexes may be more effective at suppressing prey populations.

(6) Integrated pest-management strategies that exploit dropping by pest species in response to biological control predators could have significant consequences for pest survival, growth, reproduction, and subsequent damage to crops. This may involve managing the agricultural environment such that conditions make dropping unprofitable for pests.

(7) There is much still to learn about what influences the cost-benefit framework of this under-appreciated antipredator defence and what role it played in the evolution of insect flight. Its potential to improve agricultural pest control is also, at present, little explored. To investigate all these avenues, developing an understanding of the inter-related variables at play will be key, as will studies that use natural conditions as far as possible.

\section{ACKNOWLEDGEMENTS}

We thank two referees for very helpful comments and both the Perry Foundation and the University of St Andrews for funding. 


\section{REFERENCES}

Agabiti, B., WASSENAAR, R. J. \& WindeR, L. (2016). Dropping behaviour of pea aphid nymphs increases their development time and reduces their reproductive capacity as adults. PeerJ 4, e2236.

AwaN, M. S. (1985). Anti-predator ploys of Heliothis punctiger (Lepidoptera, Noctuidae) caterpillars against the predator Oechalia schellenbergii (Hemiptera, Pentatomidae). Australian Journal of Zoology 33, 885-890.

Barnett, A. A., ANDrade, E. S., Ferreira, M. C., Soares, J. B. G., DA Silva, V. F. \& DE OLIVEIRA, T. G. (2015). Primate predation by black hawk-eagle (Spizaetus tyrannus) in Brazilian Amazonia. Journal of Raptor Research 49, 105-107.

Barnett, A. A., De Oliveira, T., DA Silva, R. F. S., Teixeira, S. D., TodD, L. M. \& Boyle, S. A. (2018). Honest error, precaution or alertness advertisement? Reactions to vertebrate pseudopredators in red-nosed cuxius (Chiropotes albinasus), a high-canopy neotropical primate. Ethology 124, 177-187.

Barnett, A. A., Silla, J. M., De Oliveira, T., Boyle, S. A., Bezerra, B. M., SPironello, W. R., SetZ, E. Z., DA Silva, R. F., De Albuquerque Teixeira, S., TodD, L. M. \& PINTO, L. P. (2017). Run, hide, or fight: anti-predation strategies in endangered rednosed cuxiu (Chiropotes albinasus, Pitheciidae) in southeastern Amazonia. Primates $\mathbf{5 8}, 353-360$.

Bass, C., Denholm, I., Williamson, M. S. \& Nauen, R. (2015). The global status of insect resistance to neonicotinoid insecticides. Pesticide Biochemistry and Physiology 121, 78-87.

Bass, C., Puinean, A. M., Zimmer, C. T., Denholm, I., Field, L. M., Foster, S. P., Gutbrod, O., NAUEN, R., Slater, R. \& Williamson, M. S. (2014). The evolution of insecticide resistance in the peach potato aphid, Myzus persicae. Insect Biochemistry and Molecular Biology 51, 41-51.

Bateman, A. W., Vos, M. \& ANHolt, B. R. (2014). When to defend: Antipredator defenses and the predation sequence. American Naturalist 183, 847-855.

BAteman, P. W. \& Fleming, P. A. (2009). To cut a long tail short: a review of lizard caudal autotomy studies carried out over the last 20 years. Journal of Zoology 277, 1-14.

BEN-ARI, M., GISH, M. \& INBAR, M. (2015). Walking aphids can partake in within-field dispersal to distant plants. Basic and Applied Ecology 16, 162-171.

BEN-ARI, M. \& INBAR, M. (2013). When herbivores eat predators: predatory insects effectively avoid incidental ingestion by mammalian herbivores. PLoS One 8, e56748.

BierzychudeK, P., WARner, K. A., MCHugh, A. \& Thomas, L. (2009). Testing the hostfinding ability of a monophagous caterpillar in the field. Ecological Entomology 34, 632-637.

Blackledge, T. A. \& PiCKetT, K. M. (2000). Predatory interactions between mud-dauber wasps (Hymenoptera, Sphecidae) and Argiope (Araneae, Araneidae) in captivity. Journal of Arachnology 28, 211-216.

Blacquière, T., Smagghe, G., van Gestel, C. A. M. \& Mommaerts, V. (2012). Neonicotinoids in bees: a review on concentrations, side-effects and risk assessment. Ecotoxicology 21, 973-992.

BRAENDLE, C. \& WeISSER, W. W. (2001). Variation in escape behavior of red and green clones of the pea aphid. Journal of Insect Behavior 14, 497-509.

BRITTAIN, J. E. \& EIKELAND, T. J. (1988). Invertebrate drift - A review. Hydrobiologia 166, 77-93. 
Brodsky, L. M. \& BARLOW, C. A. (1986). Escape responses of the pea aphid, Acyrthosiphon pisum (Harris) (Homoptera, Aphididae) - Influence of predator type and temperature. Canadian Journal of Zoology-Revue Canadienne De Zoologie 64, 937-939.

Brown, H. D. (1974). Defensive behavior of the wheat aphid Schizaphis graminum Hemiptera Homoptera Aphididae against Coccinellidae. Journal of Entomology Series A General Entomology 48, 157-165.

BULlOCK, T. H. (1953). Predator recognition and escape responses of some intertidal gastropods in presence of starfish. Behaviour 5, 130-140.

CAro, T. (2005). Antipredator Defenses in Birds and Mammals. University of Chicago Press, Chicago.

CAstellanos, I. \& BARBosa, P. (2006). Evaluation of predation risk by a caterpillar using substrate-borne vibrations. Animal Behaviour 72, 461-469.

CAstellanos, I. \& BARBosa, P. (2011). Dropping from host plants in response to predators by a polyphagous caterpillar. Journal of the Lepidopterists' Society 65, 270-272.

Castellanos, I., Barbosa, P., Zuria, I., TAmmaru, T. \& Christman, M. C. (2011). Contact with caterpillar hairs triggers predator-specific defensive responses. Behavioral Ecology 22, 1020-1025.

Chambers, R. J., Sunderland, K. D., Stacey, D. L. \& Wyatt, I. J. (1986). Control of cereal aphids in winter wheat by natural enemies: aphid-specific predators, parasitoids and pathogenic fungi. Annals of Applied Biology 108, 219-231.

ChaU, A. \& MACKAUER, M. (1997). Dropping of pea aphids from feeding site: A consequence of parasitism by the wasp, Monoctonus paulensis. Entomologia Experimentalis et Applicata 83, 247-252.

Clegg, J. M. \& BARlow, C. A. (1982). Escape behavior of the pea aphid Acyrthosiphon pisum (Harris) in response to alarm pheromone and vibration. Canadian Journal of Zoology-Revue Canadienne De Zoologie 60, 2245-2252.

Cloudsley-Thompson, J. L. (1995). A review of the anti-predator devices of spiders. Bulletin of the British Arachnological Society 10, 81-96.

Colfer, R. G. \& RosenHeIM, J. A. (2001). Predation on immature parasitoids and its impact on aphid suppression. Oecologia 126, 292-304.

CorCoran, A. J., WAGNER, R. D. \& CONNER, W. E. (2013). Optimal predator risk assessment by the sonar-jamming Arctiine moth Bertholdia trigona. PLoS One 8, e63609.

Cornell, J. C., StAMP, N. E. \& Bowers, M. D. (1987). Developmental change in aggregation, defense and escape behavior of buckmoth caterpillars, Hemileuca lucina (Saturniidae). Behavioral Ecology and Sociobiology 20, 383-388.

Costanza, R., D'Arge, R., DE Groot, R., FArber, S., Grasso, M., HANNON, B., LimburG, K., Naeem, S., O'Neill, R. V., Paruelo, J., Raskin, R. G., Sutton, P. \& Van DeN BeLt, M. (1997). The value of the world's ecosystem services and natural capital. Nature 387, 253.

Cox, D. L. \& PotTER, D. A. (1990). Aerial dispersal behavior of the bagworm. Journal of Arboriculture 16, 242-243.

Crowder, D. W. \& JABBOUR, R. (2014). Relationships between biodiversity and biological control in agroecosystems: Current status and future challenges. Biological Control 75, 8-17.

DAY, K. R., Docherty, M., LeATHER, S. R. \& KIDD, N. A. C. (2006). The role of generalist insect predators and pathogens in suppressing green spruce aphid populations through direct mortality and mediation of aphid dropping behavior. Biological Control 38, $233-246$. 
Dayton, P. K., Rosenthal, R. J., Mahen, L. C. \& Antezana, T. (1977). Population structure and foraging biology of the predaceous Chilean asteroid Meyenaster gelatinosus and the escape biology of its prey. Marine Biology 39, 361-370.

DE LunA, A. G., SANMiguel, R., Di Fiore, A. \& FernandeZ-DuQue, E. (2010). Predation and predation attempts on red titi monkeys (Callicebus discolor) and equatorial sakis (Pithecia aequatorialis) in Amazonian Ecuador. Folia Primatol (Basel) 81, 86-95.

De Souza Martins, S., De Lima, E. M. \& DE Sousa E Silva, J. (2005). Predation of a bearded saki (Chiropotes utahicki) by a harpy eagle (Harpia harpyja). Neotropical Primates 13, 7-10.

DEDRYVER, C.-A., LE RALEC, A. \& FABRE, F. (2010). The conflicting relationships between aphids and men: A review of aphid damage and control strategies. Comptes Rendus Biologies 333, 539-553.

Dill, L. M., Fraser, A. H. G. \& RoitBerG, B. D. (1990). The economics of escape behavior in the pea aphid, Acrythosiphon pisum. Oecologia 83, 473-478.

Dion, E., Polin, S. E., SimON, J. C. \& OUTREMAN, Y. (2011). Symbiont infection affects aphid defensive behaviours. Biol Lett 7, 743-746.

DiXON, A. F. G. (1958). The escape responses shown by certain aphids to the presence of the coccinellid Adalia decempunctata (L.). Transactions of the Royal Entomological Society of London 110, 319-334.

DiXON, P. L. \& MCKInLAY, R. G. (1992). Pitfall trap catches of and aphid predation by Pterostichus melanarius and Pterostichus madidus in insecticide treated and untreated potatoes. Entomologia Experimentalis et Applicata 64, 63-72.

DöRING, T. F. (2014). How aphids find their host plants, and how they don't. Annals of Applied Biology 45, 3-26.

Dudley, R., Byrnes, G., Yanoviak, S. P., Borrell, B., Brown, R. M. \& McGuire, J. A. (2007). Gliding and the functional origins of flight: Biomechanical novelty or necessity? Annual Review of Ecology, Evolution, and Systematics 38, 179-201.

DudLEY, R. \& YANOVIAK, S. P. (2011). Animal aloft: The origins of aerial behavior and flight. Integrative and Comparative Biology 51, 926-936.

Duran Prieto, J., Trotta, V., Fanti, P., Castane, C. \& Battaglia, D. (2016). Predation by Macrolophus pygmaeus (Hemiptera: Miridae) on Acyrthosiphon pisum (Hemiptera: Aphididae): Influence of prey age/size and predator's intraspecific interactions. European Journal of Entomology 113, 37-43.

EMERSON, S. B. \& KoEHL, M. A. R. (1990). The interaction of behavioral and morphological change in the evolution of a novel locomotor type - Flying frogs. Evolution 44, 19311946.

ENDLER, J. A. (1991). Interactions between predators and prey. In Behavioural Ecology: An Evolutionary Approach (ed. J. R. Krebs and N. B. Davies). Blackwell Scientific Publications, Oxford.

EVANS, H. F. (1976). Role of predator-prey size ratio in determining efficiency of capture by Anthocoris nemorum and escape reactions of its prey, Acyrthosiphon pisum. Ecological Entomology 1, 85-90.

Farhoudi, F., Allahyari, H., TABadKani, S. M. \& Gholizadeh, M. (2014). Prey preference of Aphidoletes aphidimyza on Acyrthosiphon pisum: Effect of prey color and size. Journal of Insect Behavior 27, 776-785.

Fievet, V., Dedryver, C.-A., Plantegenest, M., Simon, J.-C. \& Outreman, Y. (2007). Aphid colony turn-over influences the spatial distribution of the grain aphid Sitobion avenae over the wheat growing season. Agricultural and Forest Entomology 9, 125134. 
FiLl, A., LONG, E. Y. \& FINKE, D. L. (2012). Non-consumptive effects of a natural enemy on a non-prey herbivore population. Ecological Entomology 37, 43-50.

FitzPatrick, S. M., Troubridge, J. T. \& Maurice, C. (1994). Parasitoids of blackheaded fireworm (Rhopobota naevana Hbn.) larvae on cranberries, and larval escape behaviour. Journal of the Entomological Society of British Columbia 91, 73-74.

Francke, D. L., Harmon, J. P., HARVeY, C. T. \& IVES, A. R. (2008). Pea aphid dropping behavior diminishes foraging efficiency of a predatory ladybeetle. Entomologia Experimentalis et Applicata 127, 118-124.

Fuiman, L. A. \& MAgurRAN, A. E. (1994). Development of predator defenses in fishes. Reviews in Fish Biology and Fisheries 4, 145-183.

Geiger, F., Bengtsson, J., Berendse, F., Weisser, W. W., Emmerson, M., Morales, M. B., Ceryngier, P., Litra, J., Tscharntke, T., Winqvist, C., Eggers, S., Bommarco, R., PÄrt, T., Bretagnolle, V., Plantegenest, M., Clement, L. W., ET AL. (2010). Persistent negative effects of pesticides on biodiversity and biological control potential on European farmland. Basic and Applied Ecology 11, 97-105.

GentZ, M. C., Murdoch, G. \& KING, G. F. (2010). Tandem use of selective insecticides and natural enemies for effective, reduced-risk pest management. Biological Control 52, 208-215.

GILlESPIE, D. R. \& ACHEAMPONG, S. (2012). Dropping behaviour in Aulacorthum solani (Hemiptera: Aphididae) following attack by Aphidus ervi (Hymenoptera: Braconidae): are sticky stem bands a useful integrated pest management method? The Canadian Entomologist 144, 589-598.

GILlis, G. B., BONVINI, L. A. \& IRSCHICK, D. J. (2009). Losing stability: tail loss and jumping in the arboreal lizard Anolis carolinensis. Journal of Experimental Biology 212, 604 609.

Gish, M., DAFNI, A. \& INBAR, M. (2010). Mammalian herbivore breath alerts aphids to flee host plant. Curr Biol 20, R628-629.

GiSH, M., DAFNI, A. \& INBAR, M. (2011). Avoiding incidental predation by mammalian herbivores: accurate detection and efficient response in aphids. Naturwissenschaften 98, 731-738.

GISH, M., DAFNI, A. \& INBAR, M. (2012). Young aphids avoid erroneous dropping when evading mammalian herbivores by combining input from two sensory modalities. PLoS One 7, e32706.

GISH, M. \& INBAR, M. (2006). Host location by apterous aphids after escape dropping from the plant. Journal of Insect Behavior 19, 143-153.

Goulson, D. \& KLEIJN, D. (2013). REVIEW: An overview of the environmental risks posed by neonicotinoid insecticides. Journal of Applied Ecology 50, 977-987.

Greeney, H. F., DYer, L. A. \& SMILANICH, A. M. (2012). Feeding by lepidopteran larvae is dangerous: A review of caterpillars' chemical, physiological, morphological, and behavioral defenses against natural enemies. Invertebrate Survival Journal 9, 7-34.

GreZ, A. A., ZAVIEZO, T. \& MANCILlA, A. (2011). Effect of prey density on intraguild interactions among foliar- and ground-foraging predators of aphids associated with alfalfa crops in Chile: a laboratory assessment. Entomologia Experimentalis et Applicata 139, 1-7.

GROss, P. (1993). Insect behavioral and morphological defenses against parasitoids. Annual Review of Entomology 38, 251-273.

HAEMIG, P. D. (1997). Effects of birds on the intensity of ant rain: A terrestrial form of invertebrate drift. Animal Behaviour 54, 89-97. 
HARRISON, K. V. \& PREISSER, E. L. (2016). Dropping behavior in the pea aphid (Hemiptera: Aphididae): How does environmental context affect antipredator responses? Journal of Insect Science 16, 89.

HASENFUSS, I. (2002). A possible evolutionary pathway to insect flight starting from lepismatid organization. Journal of Zoological Systematics and Evolutionary Research 40, 65-81.

Hedenstrom, A. \& Rosen, M. (2001). Predator versus prey: on aerial hunting and escape strategies in birds. Behavioral Ecology 12, 150-156.

HofFMAN, D. L. (1980). Defensive responses of marine gastropods (Prosobranchia, Trochidae) to certain predatory seastars and the dire whelk, Searlesia dira (Reeve). Pacific Science 34, 233-243.

HoKi, E., LOSEY, J. \& UGINe, T. A. (2014). Comparing the consumptive and non-consumptive effects of a native and introduced lady beetle on pea aphids (Acyrthosiphon pisum). Biological Control 70, 78-84.

Honma, A., MAPPes, J. \& VALKOnEN, J. K. (2015). Warning coloration can be disruptive: aposematic marginal wing patterning in the wood tiger moth. Ecology and Evolution 5, 4863-74.

HumPhreYs, R. K. \& RuXTON, G. D. (2018). A review of thanatosis (death feigning) as an anti-predator behaviour. Behavioral Ecology and Sociobiology 72, 22.

INGERSLEW, K. S. \& FINKE, D. L. (2017). Mechanisms underlying the nonconsumptive effects of parasitoid wasps on aphids. Environmental Entomology 46, 75-83.

JACKSON, R. R., ROWE, R. J. \& WILCOX, R. S. (1993). Antipredator defenses of Argiope appensa (Araneae, Araneidae), a tropical orb-weaving spider. Journal of Zoology 229, $121-132$.

JACKSON, S. (2012). Gliding Mammals of the World. CSIRO Publishing, Collingwood, Australia.

JACKSON, S. M. (2000). Glide angle in the genus Petaurus and a review of gliding in mammals. Mammal Review 30, 9-30.

Johnson, C. E. (1925). Kingfisher and Copper's hawk. Auk 42, 585-586.

Johnson, M. L., Armitage, S., Scholz, B. C. G., Merritt, D. J., CriBB, B. W. \& Zalucki, M. P. (2007). Predator presence moves Helicoverpa armigera larvae to distraction. Journal of Insect Behavior 20, 1-18.

KAmbreKar, D. N., Guledgudda, S. S., KATTI, A. \& MohanKumar. (2015). Impact of climate change on insect pests and their natural enemies. Karnataka Journal of Agricultural Sciences 28, 814-816.

KeISER, C. N., Mondor, E. B. \& Koenig, W. (2015). Cues of predation risk induce instarand genotype-specific changes in pea aphid colony spatial structure. Ethology 121, 144-151.

KIRBY, R. E. \& FULLER, M. R. (1978). Observations and reinterpretation of kingfisher-raptor interactions. Auk 95, 598-599.

Krauss, J., Gallenberger, I. \& StefFan-Dewenter, I. (2011). Decreased functional diversity and biological pest control in conventional compared to organic crop fields. PLoS One 6, e19502.

Kunert, G., Belz, E., Simon, J.-C., Weisser, W. W. \& Outreman, Y. (2010). Differences in defensive behaviour between host-adapted races of the pea aphid. Ecological Entomology 35, 147-154.

LAM, K. K. Y. (2002). Escape responses of intertidal gastropods on a subtropical rocky shore in Hong Kong. Journal of Molluscan Studies 68, 297-306.

LATTA, B. (1987). Adaptive and non-adaptive suicide in aphids. Nature 330, 701-701. 
LAVy, O., Sher, N., MaliK, A. \& ChiEl, E. (2015). Do bacterial symbionts govern aphid's dropping behavior? Environmental Entomology 44, 588-92.

Lewis, W. J., VAn Lenteren, J. C., Phatak, S. C. \& Tumlinson, J. H. (1997). A total system approach to sustainable pest management. Proceedings of the National Academy of Sciences 94, 12243.

LiMA, S. L. (1993). Ecological and evolutionary perspectives on escape from predatory attack: A survey of North American birds. The Wilson Bulletin 105, 1-47.

Lledo-Ferrer, Y., Hidalgo, A., Heymann, E. W. \& Peláez, F. (2009). Field observation of predation of a slate-colored hawk, Leucopternis schistacea, on a juvenile saddle-back tamarin, Saguinus fuscicollis. Neotropical Primates 16, 82-84.

LOHRL, H. (1978). Das 'Nachsturzen' - eine reflexartige Reaktion, entfallene Beute wieder zu erlangen. Journal fuer Ornithologie 119, 325-329.

LONG, E. Y. \& FINKE, D. L. (2014). Contribution of predator identity to the suppression of herbivores by a diverse predator assemblage. Environmental Entomology 43, 569576.

LOSEY, J. E. \& DENNO, R. F. (1998a). Interspecific variation in the escape responses of aphids: effect on risk of predation from foliar-foraging and ground-foraging predators. Oecologia 115, 245-252.

LOSEY, J. E. \& DENNO, R. F. (1998b). Positive predator-predator interactions: Enhanced predation rates and synergistic suppression of aphid populations. Ecology 79, 21432152.

LOSEY, J. E. \& DENNO, R. F. (1998c). The escape response of pea aphids to foliar-foraging predators: factors affecting dropping behaviour. Ecological Entomology 23, 53-61.

LOWE, H. J. B. \& TAYLOR, L. R. (1964). Population parameters, wing production and behaviour in red and green Acyrthosiphon pisum (Harris) (Homoptera: Aphididae.). Entomologia Experimentalis et Applicata 7, 287-295.

LuCAS, E., CODERRE, D. \& BRODEUR, J. (1997). Instar-specific defense of Coleomegilla maculata lengi (Col.: Coccinellidae): Influence on attack success of the intraguild predator Chrysoperla rufilabris (Neur.: Chrysopidae). Entomophaga 42, 3-12.

MA, G. \& MA, C. S. (2012). Climate warming may increase aphids' dropping probabilities in response to high temperatures. Journal of Insect Physiology 58, 1456-62.

MCAlLister, M. K. \& RoitBerg, B. D. (1987). Adaptive suicidal behavior in pea aphids. Nature 328, 797-799.

McAllister, M. K., Roitberg, B. D. \& Weldon, K. L. (1990). Adaptive suicide in pea aphids - Decisions are cost sensitive. Animal Behaviour 40, 167-175.

McCAY, M. G. (2001). Aerodynamic stability and maneuverability of the gliding frog Polypedates dennysi. Journal of Experimental Biology 204, 2817-2826.

MCGuire, J. A. \& DudLeY, R. (2005). The cost of living large: Comparative gliding performance in flying lizards (Agamidae: Draco). American Naturalist 166, 93-106.

MCKAYE, K. R. (1981). Field observation on death feigning - A unique hunting behaviour by the predatory cichlid, Haplochromis livingdtoni, of Lake Malawi. Environmental Biology of Fishes 6, 361-365.

Meisner, M., Harmon, J. P., HARvey, C. T. \& IVES, A. R. (2011). Intraguild predation on the parasitoid Aphidius ervi by the generalist predator Harmonia axyridis: the threat and its avoidance. Entomologia Experimentalis et Applicata 138, 193-201.

Meresman, Y., BEN-ARI, M. \& InBAR, M. (2017). Turning in mid-air allows aphids that flee the plant to avoid reaching the risky ground. Integrative Zoology 12, 409-420.

Michaud, J. P. (2010). Implications of Climate Change for Cereal Aphids on the Great Plains of North America. In Aphid Biodiversity under Environmental Change: Patterns and 

Netherlands.

Miller, L. A. \& Olesen, J. (1979). Avoidance behaviour in green lacewings: 1. Behavior of free flying green lacewings to hunting bats and ultrasound. Journal of Comparative Physiology 131, 113-120.

Miller, L. A. \& SuRlYKKe, A. (2001). How some insects detect and avoid being eaten by bats: Tactics and countertactics of prey and predator. Bioscience 51, 570-581.

MinORETTI, N. \& WeISSER, W. W. (2000). The impact of individual ladybirds (Coccinella septempunctata, Coleoptera: Coccinellidae) on aphid colonies. European Journal of Entomology 97, 475-479.

Montgomery, M. E. \& NAUlT, L. R. (1977). Comparative response of aphids to alarm pheromone, (E)-beta- farnesene. Entomologia Experimentalis et Applicata 22, 236242.

MoORE, R. G. \& HANKS, L. M. (2004). Aerial dispersal and host plant selection by neonate Thyridopteryx ephemeraeformis (Lepidoptera : Psychidae). Ecological Entomology 29, 327-335.

MoRI, A. \& HiKIDA, T. (1994). Field observations on the social behavior of the flying lizard, Draco volans sumatranus, in Borneo. Copeia 1, 124-130.

Muratori, F. B., RouyAR, A. \& HANCE, T. (2014). Clonal variation in aggregation and defensive behavior in pea aphids. Behavioral Ecology 25, 901-908.

NAmAn, S. M., Rosenfeld, J. S. \& RichaRdSON, J. S. (2016). Causes and consequences of invertebrate drift in running waters: from individuals to populations and trophic fluxes. Canadian Journal of Fisheries and Aquatic Sciences 73, 1292-1305.

NARAYANDAS, G. K. \& AlYOKHIN, A. V. (2006). Diurnal patterns in host finding by potato aphids, Macrosiphum euphorbiae (Homoptera: Aphididae). Journal of Insect Behavior 19, 347-356.

NAult, L., MONTGOMERY, M. \& Bowers, W. (1976). Ant-aphid association: role of aphid alarm pheromone. Science 192, 1349-1351.

NELSON, E. H. (2007). Predator avoidance behavior in the pea aphid: costs, frequency, and population consequences. Oecologia 151, 22-32.

Nelson, E. H., Matthews, C. E. \& Rosenheim, J. A. (2004). Predators reduce prey population growth by inducing changes in prey behavior. Ecology 85, 1853-1858.

Nelson, E. H. \& RosenHEIM, J. A. (2006). Encounters between aphids and their predators: the relative frequencies of disturbance and consumption. Entomologia Experimentalis et Applicata 118, 211-219.

NIKU, B. (1976). Some consequences of the drop reaction of Acyrthosiphon pisum for the larvae of Syrphus corollae. Entomophaga 21, 257-264.

Obermaier, E., Heisswolf, A., Poethke, H., Randlkofer, B. \& Meiners, T. (2008). Plant architecture and vegetation structure: Two ways for insect herbivores to escape parasitism. European Journal of Entomology 105, 233-240.

OHNo, T. \& MiYatake, T. (2007). Drop or fly? Negative genetic correlation between deathfeigning intensity and flying ability as alternative anti-predator strategies. Proceedings of the Royal Society B: Biological Sciences 274, 555-560.

OHZORA, Y. \& YANO, S. (2011). Voluntary falling in spider mites in response to different ecological conditions at landing points. Journal of Insect Behavior 24, 274-281.

Perović, D. J., Johnson, M.-L., ScholZ, B. \& ZAlucki, M. P. (2008). The mortality of Helicoverpa armigera (Hübner) (Lepidoptera: Noctuidae) neonate larvae in relation to drop-off and soil surface temperature: the dangers of bungy jumping. Australian Journal of Entomology 47, 289-296. 
Phelan, P. L., Montgomery, M. E. \& NAUlt, L. R. (1976). Orientation and locomotion of apterous aphids dislodged from their hosts by alarm pheromone. Annals of the Entomological Society of America 69, 1153-1156.

RAAK-VAN DEN BERG, C. L., DE LANGE, H. J. \& VAN LENTEREN, J. C. (2012). Intraguild predation behaviour of ladybirds in semi-field experiments explains invasion success of Harmonia axyridis. PLoS One 7, e40681.

Ratcliffe, J. M., Fullard, J. H., ARthur, B. J. \& Hoy, R. R. (2011). Adaptive auditory risk assessment in the dogbane tiger moth when pursued by bats. Proceedings of the Royal Society B: Biological Sciences 278, 364-370.

RIBAK, G., GISH, M., WEIHS, D. \& INBAR, M. (2013). Adaptive aerial righting during the escape dropping of wingless pea aphids. Current Biology 23, R102-103.

RoITBERG, B. D. \& MYERS, J. H. (1978). Adaptation of alarm pheromone responses of pea aphid Acyrthosiphon pisum (Harris). Canadian Journal of Zoology-Revue Canadienne De Zoologie 56, 103-108.

RoITBERG, B. D. \& MYERS, J. H. (1979). Behavioural and physiological adaptations of pea aphids (Homoptera: Aphididae) to high ground temperatures and predator disturbance. Canadian Entomologist 111, 515-519.

RoitberG, B. D., Myers, J. H. \& Frazer, B. D. (1979). Influence of predators on the movement of apterous pea aphids between plants. Journal of Animal Ecology 48, $111-122$.

Rosen, M. J., Levin, E. C. \& Hoy, R. R. (2009). The cost of assuming the life history of a host: acoustic startle in the parasitoid fly Ormia ochracea. Journal of Experimental Biology 212, 4056-4064.

Rosenheim, J. A., KaYA, H. K., Ehler, L. E., Marois, J. J. \& Jaffee, B. A. (1995). Intraguild predation among biological-control agents: Theory and evidence. Biological Control 5, 303-335.

Ruth, W. E., McNew, R. W., CAVEs, D. W. \& Elkenbary, R. D. (1975). Greenbugs (Hom.: Aphididae) forced from host plants by Lysiphlehus testaceipes (Hym.: Braconidae). Entomophaga 20, 65-71.

RuXton, G. D., Sherratt, T. N. \& SPeED, M. P. (2004). Avoiding attack: the evolutionary ecology of crypsis, warning signals and mimicry. Oxford University Press, Oxford.

SAto, S., YASUdA, H. \& EvAns, E. W. (2005). Dropping behaviour of larvae of aphidophagous ladybirds and its effects on incidence of intraguild predation: interactions between the intraguild prey, Adalia bipunctata (L.) and Coccinella septempunctata (L.), and the intraguild predator, Harmonia axyridis Pallas. Ecological Entomology 30, 220-224.

Schmidt, M. H., Lauer, A., Purtauf, T., Thies, C., Schaefer, M. \& Tscharntke, T. (2003). Relative importance of predators and parasitoids for cereal aphid control. Proceedings of the Royal Society B: Biological Sciences 270, 1905-1909.

Schuett, W., Dall, S. R., Baeumer, J., Kloesener, M. H., NAKagawa, S., Beinlich, F. \& EGGERS, T. (2011). Personality variation in a clonal insect: the pea aphid, Acyrthosiphon pisum. Developmental Psychobiology 53, 631-640.

Schuett, W., DAll, S. R., Kloesener, M. H., BAeumer, J., Beinlich, F. \& EgGers, T. (2015). Life-history trade-offs mediate 'personality' variation in two colour morphs of the pea aphid, Acyrthosiphon pisum. Journal of Animal Ecology 84, 90-101.

SchwartzberG, E. G., Kunert, G., Röse, U. S. R., Gershenzon, J. \& Weisser, W. W. (2008). Alarm pheromone emission by pea aphid, Acyrthosiphon pisum, clones under predation by lacewing larvae. Entomologia Experimentalis et Applicata 128, 403409.

SKINNER, M. P. (1928). Kingfisher and sharp-shinned hawk. Auk 45, 100-101. 
SocHA, J. J. (2002). Kinematics - Gliding flight in the paradise tree snake. Nature 418, 603604.

Springate, S. \& COLVIN, J. (2012). Pyrethroid insecticide resistance in British populations of the cabbage whitefly, Aleyrodes proletella. Pest Management Science 68, 260-267.

STACEY, D. A. \& Fellowes, M. D. (2002). Influence of temperature on pea aphid Acyrthosiphon pisum (Hemiptera: Aphididae) resistance to natural enemy attack. Bulletin of Entomological Research 92, 351-357.

Stadler, B., Weisser, W. W. \& Houston, A. I. (1994). Defense reactions in aphids - The influence of state and future reproductive success. Journal of Animal Ecology 63, 419-430.

SUGIURA, S. \& YAMAZAKI, K. (2006). The role of silk threads as lifelines for caterpillars: pattern and significance of lifeline-climbing behaviour. Ecological Entomology 31, $52-57$.

SUZUKI, N. \& IDE, T. (2007). The foraging behaviors of larvae of the ladybird beetle, Coccinella septempunctata L., (Coleoptera: Coccinellidae) towards ant-tended and non-ant-tended aphids. Ecological Research 23, 371-378.

Symondson, W. O. C., Sunderland, K. D. \& Greenstone, M. H. (2002). Can generalist predators be effective biocontrol agents? Annual Review of Entomology 47, 561-594.

TERRY, I., BRADLEY, J. R. \& VANDUYN, J. W. (1989). Establishment of early instar Heliothis zea on soybeans. Entomologia Experimentalis et Applicata 51, 233-240.

ToBler, M. (2005). Feigning death in the central American cichlid Parachromis friedrichsthalii. Journal of Fish Biology 66, 877-881.

TomLINSON, I. (1987). Adaptive and non-adaptive suicide in aphids. Nature 330, 701-701.

Traugott, M., Bell, J. R., Raso, L., Sint, D. \& Symondson, W. O. C. (2012). Generalist predators disrupt parasitoid aphid control by direct and coincidental intraguild predation. Bulletin of Entomological Research 102, 239-247.

Uetz, G. W., Boyle, J., Hieber, C. S. \& WilcoX, R. S. (2002). Antipredator benefits of group living in colonial web-building spiders: the 'early warning' effect. Animal Behaviour 63, 445-452.

Villagra, C. A., Ramírez, C. C. \& Niemeyer, H. M. (2002). Antipredator responses of aphids to parasitoids change as a function of aphid physiological state. Animal Behaviour 64, 677-683.

Vitt, L. J., CoOper, J. W. E., Perera, A. \& PÉReZ-Mellado, V. (2002). Escaping predators on vertical surfaces: Lacerta perspicillata in limestone quarries of Lithaca. Canadian Journal of Zoology 80, 1803-1809.

von Berg, K., Thies, C., TscharntKe, T. \& ScheU, S. (2009). Cereal aphid control by generalist predators in presence of belowground alternative prey: Complementary predation as affected by prey density. Pedobiologia 53, 41-48.

Wang, L., Hui, C., SANDhu, H. S., Li, Z. \& ZhaO, Z. (2015). Population dynamics and associated factors of cereal aphids and armyworms under global change. Scientific Reports 5, 18801.

WINDER, L. (1990). Predation of the cereal aphid Sitobion avenae by polyphagous predators on the ground. Ecological Entomology 15, 105-110.

Winder, L., AleXander, C. J., Woolley, C., Perry, J. N. \& Holland, J. M. (2014). Cereal aphid colony turnover and persistence in winter wheat. PLoS One 9, e106822.

Winder, L., Hirst, D. J., CARTER, N., Wratten, S. D. \& SopP, P. I. (1994). Estimating predation of the grain aphid Sitobion avenae by polyphagous predators. Journal of Applied Ecology 31, 1-12.

WoOster, D. \& SiH, A. (1995). A review of the drift and activity responses of stream prey to predator presence. Oikos 73, 3-8. 
WRIGHT, P. C. (1998). Impact of predation risk on the behaviour of Propithecus diadema ewardsi in the rain forest of Madagascar. Behaviour 135, 483-512.

Wyckhuys, K. A., Stone, L., DesneuX, N., Hoelmer, K. A., Hopper, K. R. \& Heimpel, G. E. (2008). Parasitism of the soybean aphid, Aphis glycines by Binodoxys communis: the role of aphid defensive behaviour and parasitoid reproductive performance. Bulletin of Entomological Research 98, 361-70.

YANOVIAK, S. P. \& DudLeY, R. (2006). The role of visual cues in directed aerial descent of Cephalotes atratus workers (Hymenoptera: Formicidae). Journal of Experimental Biology 209, 1777-1783.

YANOVIAK, S. P., DudLey, R. \& KASPARI, M. (2005). Directed aerial descent in canopy ants. Nature 433, 624.

YANOVIAK, S. P., FisheR, B. L. \& AlOnSO, A. (2008). Directed aerial descent behavior in African canopy ants (Hymenoptera: Formicidae). Journal of Insect Behavior 21, 164 171.

YANOVIAK, S. P., KASPARI, M. \& DUDLEY, R. (2009). Gliding hexapods and the origins of insect aerial behaviour. Biology Letters 5, 510-512.

YANOVIAK, S. P., MunK, Y. \& DUdLEY, R. (2011). Evolution and ecology of directed aerial descent in arboreal ants. Integrative and Comparative Biology 51, 944-56.

YANOVIAK, S. P., MunK, Y. \& DudLEY, R. (2015). Arachnid aloft: directed aerial descent in neotropical canopy spiders. Journal of the Royal Society Interface 12, 0534.

YANOVIAK, S. P., MunK, Y., KASPARI, M. \& Dudley, R. (2010). Aerial manoeuvrability in wingless gliding ants (Cephalotes atratus). Proceedings of the Royal Society B: Biological Sciences 277, 2199-2204.

YEARGAN, K. V. \& BRAMAN, S. K. (1986). Life history of the parasite Diolcogaster facetosa (Weed) (Hymenoptera: Braconidae) and its behavioral adaptation to the defensive response of a lepidopteran host. Annals of the Entomological Society of America 79, 1029-1033.

YEARGAN, K. V.\& BRAMAN, S. K. (1989). Life history of the hyperparasitoid Mesochorus discitergus (Hymenoptera, Ichneumonidae) and tactics used to overcome the defensive behavior of the green cloverworm (Lepidoptera, Noctuidae). Annals of the Entomological Society of America 82, 393-398.

Zalucki, M. P., Clarke, A. R. \& MALCOLM, S. B. (2002). Ecology and behavior of first instar larval lepidoptera. In Annual Review of Entomology, vol. 47. Annual Review of Entomology (ed. M. R. Berenbaum, R. T. Carde and G. E. Robinson), pp. 361-393.

ZENG, Y., Lin, Y., ABUNDO, A. \& DUDLEY, R. (2015). Visual ecology of directed aerial descent in first-instar nymphs of the stick insect Extatosoma tiaratum. Journal of Experimental Biology 218, 2305-2314.

Zhang, Y., Wang, X. X., ZhU, J. Y., Zhang, Z. F., Tian, H. G. \& LiU, T. X. (2016). Strategies used by two apterous strains of the pea aphid Acyrthosiphon pisum for passive dispersal. Biology Open 5, 1535-1544.

Zhou, J., Meng, L. \& LI, B. (2017). Defensive behaviors of the Oriental armyworm Mythimna separata in response to different parasitoid species (Hymenoptera: Braconidae). PeerJ 5, e3690. 